\title{
Effect of Sprue Design in Nickel-Chromium Cast Crown Margin
}

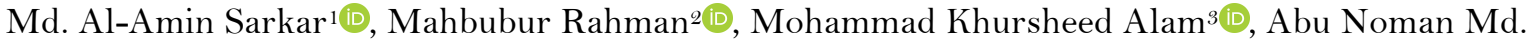 \\ Abdullah $^{4}$, Mostafa Md. Anisuzzaman ${ }^{5}(0)$
}

${ }^{1}$ Department of Prosthodontics, Dhaka Dental College Hospital, Dhaka, Bangladesh.

${ }^{2}$ Department of Prosthodontics, Bangabandhu Sheikh Mujib Medical University, Dhaka, Bangladesh.

${ }^{3}$ College of Dentistry, Jouf University, Sakakah, Al-Jouf, Saudi Arabia.

${ }^{4}$ Department of Science of Dental Materials, Shaheed Suhrawardy Medical College, Dhaka, Bangladesh.

${ }^{5}$ Department of Oral and Maxillofacial Surgery, Ibrahim Medical College (Dental Unit), Dhaka, Bangladesh.

Correspondence: Dr. Md. Al-Amin Sarkar, Department of Prosthodontics, Dhaka Dental College Hospital, Mirpur 14, Dhaka, Bangladesh. E-mail: dr.sarkar.bds@gmail.com

Academic Editor: Yuri Wanderley Cavalcanti

Received: 01 June 2020 / Review: 15 August 2020 / Accepted: 28 August 2020

How to cite: Sarkar MA, Rahman MM, Alam MK, Abdullah ANM, Anisuzzaman MM. Effect of sprue design in nickel-
chromium cast crown margin. Pesqui Bras Odontopediatria Clín Integr. 2021; $21: e 0110$.
https://doi.org/10.1590/pboci.2021.022

\begin{abstract}
Objective: To determine the effect of sprue design on the marginal accuracy of the casting. Material and Methods: It was an experimental in-vitro study. There are forty-four crowns of single sprue group with a forty-four double sprue group that was compared in 6 different locations of the margin. The sections were inspected under a microscope at 50X magnification and took a micrograph. The radius from an actual casting edge to a possibly excellent margin was then documented as marginal discrepancy (d), in $\mu \mathrm{m}$. The marginal discrepancy was documented for each of the six sections per casting. Thus 264 sections were measured for each group. Data were analysed using (ANOVA) for analysis of variance. For bivariate analyses, Chi-square and Student $t$ test were used. The significance level was set at $<0.05$. Results: The marginal discrepancy was greater in the single sprue group of cast crown $(43.1 \pm 4.74 \mu \mathrm{m})$ and in double sprue group of cast crown was less $(25.7 \pm 4.25 \mu \mathrm{m})$. This difference is statistically significant $(\mathrm{p}<0.05)$. The correlation between single sprue group of casting with a double sprue group of casting by student's t-test where determination height was $95 \%$. Conclusion: Double sprue design produces a higher accurate margin than single sprue design in the nickel-chromium alloy cast crown.
\end{abstract}

Keywords: Dental Materials; Dental Casting Investment; Dental Alloys; Chromium Alloys. 


\section{Introduction}

Casting of an alloy was one of the critical factors associated with the success of the metal restoration. Castability of an alloy faithfully reproduces the sharp detail and fine margins of the wax pattern. Many studies focused on producing a predictive index of dental alloy casting [1]. Castability of dental alloy was affected by alloy selection, pattern design, sprue technique, investment material, wax elimination procedures and melting temperature and casting procedures [2]. It was important related cast crown fabrication dimensional accuracy. A perfect margin is one of criteria of a dimensionally accurate crown. Proper sprue design makes perfect casting in all dimensions [3]. The dimensionally accurate crown must be fitted with the prepared teeth since the castability of alloy influence directly [4].

The sprue's function was to create a path through which molten metal can reach the entire mold cavity to ensure its proper filling. In crown manufacture, sprue design was an essential factor that regulations velocity and acceptable supply of molten metal into the mold. A lot of research in dental casting determines the importance of the size of the sprue and its type, shape, location, and direction. Sprue diameter may be the most important variable that controls the integrity and durability of the casting. In crown fabrication, the sprue is a variable that influences casting success.

Marginal accuracy of double sprue in titanium casting had significantly more than a single sprue because double sprue allows more metal flow in the mold cavity to record the margin's finer detail. Use sprue diameter bigger than the thickest cross-section of the casting to eradicate shrinkage porosity [5]. Most research had found a direct proportionality between flowability and channel radius [6]. Various sprue designs that include: flaring the sprue at the point of attachment, sprue diameter larger than the thickest cross-section of the pattern, long sprue for thick patterns, short sprue for thin patterns, constricted sprue juncture, and conical sprues [7].

Large angulated sprue with open vent was better than conventional straight direct sprue [8]. Also, an interesting view was the pattern should be angled downward from the sprue so that it is located in the outer lower quarter of the trailing half of the casting ring. Angulated sprue was used in this study and the pattern was an outer quarter and trailing half from the sprue [9]. Since the advent of non-precious metal for metal restoration, many new alloys have been introduced in dental profession. Nickel-chromium alloy is a base metal where nickel $80 \%$ and chromium $20 \%$ [10].

Castings made with the nickel-chrome alloy were statistically more complete than those with the other alloys. Nickel-chromium alloy offers promise as substitutes for gold alloys in casting crown prostheses [3]. Chromium oxides are extremely stable in biologic environmental conditions [11]. The sprue, burnout temperature, casting temperature, and casting technique used with non-precious alloys are significantly different from those of precious alloys [12].

Base-metal alloys desire a casting approach correctly design for their physical properties [6]. Margin sharpness was regularly the main attention at the time of checking the accuracy of dental castings. He also combined that crown finish lines and margins are usually arranged subgingivally, where biologic deliberation is an enormous concern [13]. Marginal accuracy is one of the most significant factors in the success of the longevity metal restoration. Inadequate adaptation of a cast restoration leads to teeth and periodontium destruction [14]. Ideally, the cemented crown margin meets prepared tooth margins in perfect non-detectable junctions [15]. No castings were capable of reproducing the pattern completely. Based on the theoretical calculation for clinically tolerable marginal openings, a value of $50 \mu \mathrm{m}$, which allowed $25 \mu \mathrm{m}$ for cement layer and $25 \mu \mathrm{m}$ for the deficiency of cast margin tip [16]. 
This study aims to determine the effect of sprue design on the marginal accuracy of the casting. Poor marginal fit of a crown cause dislodgement and detrimental for periodontium. A more accurate margin of a cast is acceptable during casting procedure as it is clinically acceptable [6].

\section{Material and Methods}

\section{Study Design}

It was an experimental in-vitro study where a single sprue group of 44 samples were compared with 44 samples of double sprue group [8].

\section{Sample Preparation Procedure}

A stylized die was made by a casting method with a nickel-chromium alloy, which simulated the prepared tooth for a metal crown. A cylinder shape dice was selected in perfect size than inlay casting wax was melted over it. After setting the inlay casting wax, it was removed carefully from the dice. Then the wax pattern for die transferred in the surveyor where 60 tapered bur has already been placed. The bur positioned in the circumference of the wax pattern and scraps the wax carefully to produce the 450 bevel finish line. Then the pattern was sent for casting. The casting die, which simulate a prepared tooth for metal crown. Its height was $6 \mathrm{~mm}$ and diameter was $7 \mathrm{~mm}$. Inlay casting wax (Blue shade inlay casting wax, Type-III, Mfg. Cos, Shiva Products, Maharashtra, India) was placed for coping by step-by-step waxing technique. The metal die with wax pattern was placed in sculpting dice to achieve a cylindrical external form and homogeneous in thickness as possible. Then the margin was inspected with microscope $25 \mathrm{X}$ magnification to observe any irregularity. Then it removed from the die. A total of 88 wax patterns were made in the same procedure.

The patterns were separated into two groups. One was group-A where one 10-gauge $(2.5 \mathrm{~mm}$ diameter) sprue was attached centrally to the occlusal surface so that metal flow all around equally [11]. Another group was group-B where two 10-gauge sprues were attached in occlusal-axial line angle flush with the axial surface of each side of the coping pattern. The double sprue was attached to the occlusocervical line angle to maintain equal distance from each other and the nearest distance from the margin [11]. The straight part of the sprue was $5 \mathrm{~mm}$ and terminal 450 angular part was $10 \mathrm{~mm}$, which was attached in crucible former. Then phosphate bonded investment plaster (Bellasum, Bego, Germany) was manipulate and invested in the casting ring. The investment powder was blended under vacuum for 15 seconds and again gradually vibrated into the ring, which was replete with almost $6 \mathrm{~mm}$ superior the pattern. The location of the crown pattern in the ring was considerable on the investment, so rings could be accurately oriented for casting. The investment was granted to bench set at room temperature (approximately $25^{\circ} \mathrm{C}$ ) for 45 minutes before opening burnout operation.

Burnout was completed in a burnout furnace (Roko Dental, Slaskie, Poland). The casting was formed in a centrifugal casting machine according to the manufacturer's guidance (RT 1348713; Roko Dental, Slaskie, Poland) and accepting commercially pure nickel-chromium ingots (Verabond type-5; Aalba Dent, Inc., Fairfield, CA, USA - Melting temperature $1160^{\circ} \mathrm{C}-1275^{\circ} \mathrm{C}$; Composition: Ni $77.9 \%$, Cr 12.6\%, Mo 5\%, Be-1.9\%, Al-2.9\%, Co-1.9\%. Forty-four castings were made for each group providing a total of 88 cast crowns.

After bench cooling, the casting was divested manually and sandblasted lightly with $50 \mu \mathrm{m}$ aluminum oxide braise to abolish extra investment grossly, and then the button of the castings was sectioned off. All cast crowns were ultrasonically brushed in $6 \%$ hydrochloric acid for 2 minutes. No grinding, deburring, or 
polishing was sleeked; no effort was formed to reseat the castings on the original die. All samples were made in the xerox way.

An impression of the absolute casting was made with a $9 \mathrm{~mm}$ diameter plastic ring full of light body impression material (Zhermack SpA, Badia Polesine, Italy). The circular margin was centered in the ring. After setting, the impression was detached from the ring and implanted in the matching tubular jig that advised cuts dividing the cylindrical impression into six equally sized divisions. Each division was recorded 1/6th of the test casting margin having 600 intervals. The impression of casting with double sprues were adjusted in the identical tubular jig with sprues at the location "a" and " $\mathrm{d}$ " and in case of an impression of casting with single sprue were adjusted at the location where the angle of the sprue calculated between location "b" and "c". Each section was categorized according to its location in the jig (Figure 1) [12].

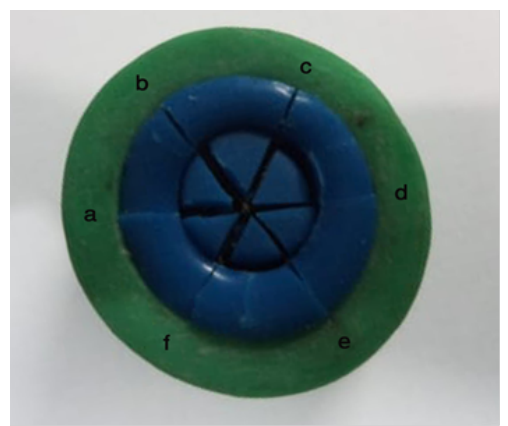

Figure 1. The impression of the margin in a different position (k).

The sections were inspected under a microscope at 50X magnification and took a micrograph. The 450 margins were coated in Adobe Photoshop CS2 9.0 software. The radius from an actual casting edge to a possibly excellent margin was then documented as marginal discrepancy (d), in $\mu \mathrm{m}$. The marginal discrepancy was documented for each of the six sections per casting. Thus 264 sections were measured for each group.

\section{Data Analysis}

Data were analysed using (ANOVA) for analysis of variance. For bivariate analyses, Chi-square and Student t-test were used. The significance level was set at $<0.05$.

\section{Ethical Aspects}

Ethical approval for this study was obtained from the Institutional review board of Bangabandhu Sheikh Mujib Medical University (I.R.B/BSMMU/2014/5260) and Bangladesh College of Physicians and Surgeons (CPS-712/2014/, 7/10/2014, PSN- 0013). The certificate wasalso obtained from the Department of Materials and Metallurgical Engineering in Bangladesh University of Engineering and Technology.

\section{Results}

Tables 1 and 2 showing the calculated value of $F$ was less than critical value of $F$ at $\alpha=0.05$, that is $p$ value was $>0.05$, which was not significant in groups $\mathrm{A}$ and $\mathrm{B}$.

The mean and standard deviation of marginal discrepancies for the group A: single sprueing group was $43.1 \pm 4.74 \mu \mathrm{m}$ and group B: double sprueing group was $25.7 \pm 4.25 \mu \mathrm{m}$. Student's t-test was used to find out the significance of difference of marginal discrepancy around the circumference of all castings between two groups group A and group B (Figure 2). 
Table 1. Marginal discrepancy of cast crown of both groups.

\begin{tabular}{|c|c|c|c|c|}
\hline \multirow[t]{2}{*}{ Position (K) } & \multicolumn{2}{|c|}{ Group A $\left(n_{1}=44\right)$} & \multicolumn{2}{|c|}{ Group B $\left(n_{2}=44\right)$} \\
\hline & Mean & $\mathrm{SD}$ & Mean & SD \\
\hline $\mathrm{a}$ & 43.6 & 11.8 & 26.0 & 7.0 \\
\hline$b$ & 43.4 & 11.6 & 24.6 & 9.5 \\
\hline $\mathrm{c}$ & 43.3 & 12.4 & 24.9 & 6.1 \\
\hline d & 41.6 & 13.5 & 25.6 & 8.6 \\
\hline e & 45.6 & 13.3 & 27 & 13.1 \\
\hline f & 41.2 & 11.8 & 25.9 & 7.9 \\
\hline
\end{tabular}

sprue cast crown; Group B = Double sprue cast crown; $\mathrm{n}_{1}=$ Sample for Group A; $\mathrm{n}_{2}=$ Sample for Group-B.

Table 2. The results of the analysis of variance test of Group A.

\begin{tabular}{ccccccc}
\hline Source & Sum of Squares & Degree of Freedom & Mean Square & F-ratio & F-critical Value & p-value \\
\hline Position & 529.75 & 5 & 105.95 & 0.687 & 2.26 & $>0.05$ \\
Error & 39809.27 & 258 & 154.30 & & & \\
\hline
\end{tabular}

Table 3. The results of the analysis of variance test of Group-B

\begin{tabular}{ccccccc}
\hline Source & Sum of Squares & Degree of Freedom & Mean Square & F-ratio & F-critical Value & p-value \\
\hline Position & 160.17 & 5 & 32.03 & 0.397 & 2.26 & $>0.05$ \\
Error & 20794.50 & 258 & 80.60 & & & \\
\hline
\end{tabular}

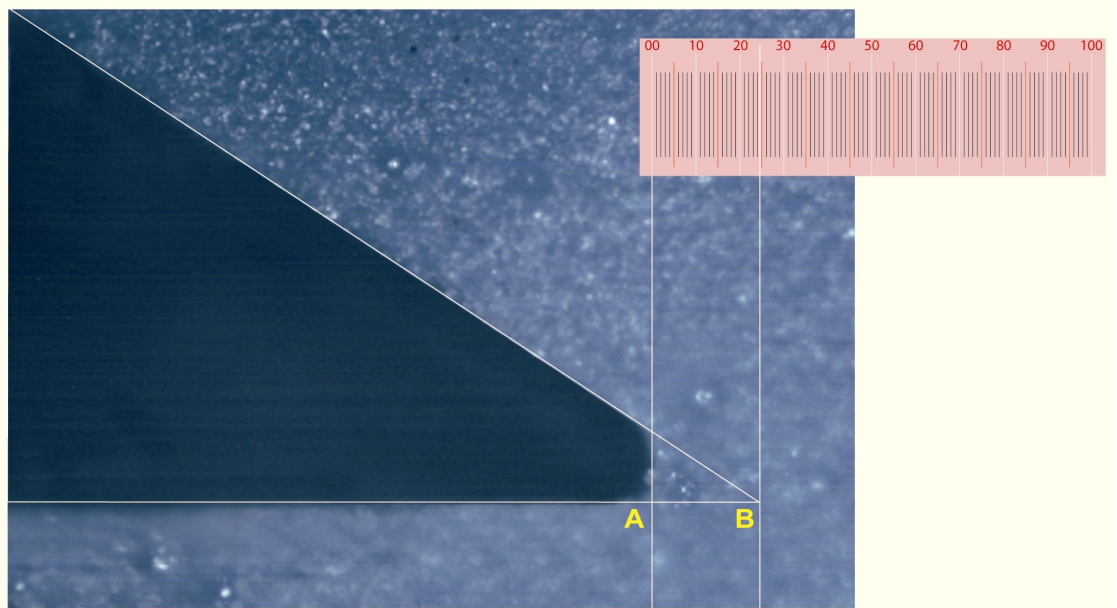

Figure 2. Cast crown margin impression's micrograph 50X. Marginal Discrepancy $\mathrm{d}=25 \mu \mathrm{m}$.

Table 4 presented that the double sprueing group had significantly less marginal discrepancy than the single sprueing group $(\mathrm{p}<0.05)$.

Table 4. Comparison of marginal discrepancies between groups.

\begin{tabular}{lccccccc}
\multicolumn{1}{c}{ Group } & $\mathbf{n}$ & Mean & SD & Calculated t-value & Degree of Freedom & Tabulated t-value & p-value \\
\hline Group A & 44 & 43.1023 & 4.74800 & 18.15 & 86 & 2.00 & $<0.05$ \\
Group B & 44 & 25.6614 & 4.25169 & & & \\
\hline
\end{tabular}

\section{Discussion}

The results of this study show that marginal discrepancy was greater in single sprueing group of cast crown where mean $43.1 \pm 4.74 \mu \mathrm{m}$ and in double sprueing group of cast crown was less where mean $25.7 \pm$ $4.25 \mu \mathrm{m}$. This difference is statistically significant $(\mathrm{p}<0.05)$. Table 4 presents the comparison between single sprueing group of casting with multiple sprueing group of casting by student's t-test where confidence level was $95 \%$. 
The above-mentioned result is supported by Chan et al. [13], which conducted a study to measure the effect of the number of sprues on the marginal accuracy of titanium casting. They found the marginal discrepancies of single sprueing group $49.8 \pm 16.4 \mu \mathrm{m}$ were significantly higher than the multiple sprueing group $32.1 \pm 12.8 \mu \mathrm{m}$. The double sprue design resulted in a relatively accurate margin than the single sprue design that was statistically significant $(\mathrm{p}<0.01)$ [13].

This study also presents no effect in sprue design in marginal discrepancy in between 6 different crown locations, which statistically not significant $(\mathrm{p}>0.05)$ in both single and double sprues cast crown. The analysis variance results of this study are listed in Tables 2 and 3 . The same result was also founded by Chan et al. [13] in titanium casting, which supports this study's result.

Influence of sprue number on the casting accuracy. They casted single and double sprue design with two different investments of each pattern. The study showed double sprue design provided better casting accuracy than single sprue design. The present study showed the double sprue design produces better marginal accuracy than single sprue design [2].

In this study, the double sprue design resulted in an accurate margin in nickel-chromium alloy cast crowns than single sprue design. The sprue number and design also are supported by Chan et al. [13]. They performed a study on the effect of sprue design on the titanium castings' roughness and porosity. They announce that in sprue number and position on roughness and porosities for the double sprue design of casting demonstrate smoother surface than the single sprue design $(\mathrm{p}<0.01)$, which almost allows with the present study [5].

Rieger et al. [6] did an experiment on sprue design on casting of base metal alloy. They take standard sprue design, which was 12-gauge plastic sprue former, $10 \mathrm{~mm}$ in length and compared with conical sprue that was 12-gauge for $1 \mathrm{~mm}$ and then flared to meet the sprue base. The study results found that the conical sprue design was superior to the standard sprue design under test conditions. No specific pattern to the casting incompleteness was shown in both groups. The surface texture of all casting was smooth in both groups. The conical sprue design, however, showed finer detail [6].

The clinically acceptable marginal discrepancy is $50 \mu \mathrm{m}$, whereas in both samples group shows within the desired limit, but double sprue group cast crown margin is more precise [16]. So, the prognosis of a crown that is made with double sprue is more admissible.

In this study, the double sprue design allowed more molten metal to enter in the mold, which resulted in a good flow of metal to the margin area in the mold that produces the margin's accuracy. Therefore regarding marginal accuracy, the basic concept of sprue design of all above mention studies supported the present study.

This study has limitations, such as all facilities of determination of marginal discrepancy were not available in the study place. The future directions are the multiple sprue design should be recommended than single sprue design to get a more accurate margin in nickel-chromium casting and to determination of marginal discrepancy, it is better in the indirect method rather than the direct method.

\section{Conclusion}

Marginal accuracy greatly affects the quality and success of a cast crown. Sprue design is one of the important factors to get appropriate casting. The casting was done in different alloy and metal with different sprue design instead of nickel-chromium alloy in the marginal accuracy of a cast crown. This study will help the clinician and laboratory technician select the appropriate number of sprues for accuracy of cast crown 
margin. Based on the research, double sprue design produces a more accurate margin than single sprue design in the nickel-chromium alloy cast crown.

\section{Authors' Contributions}

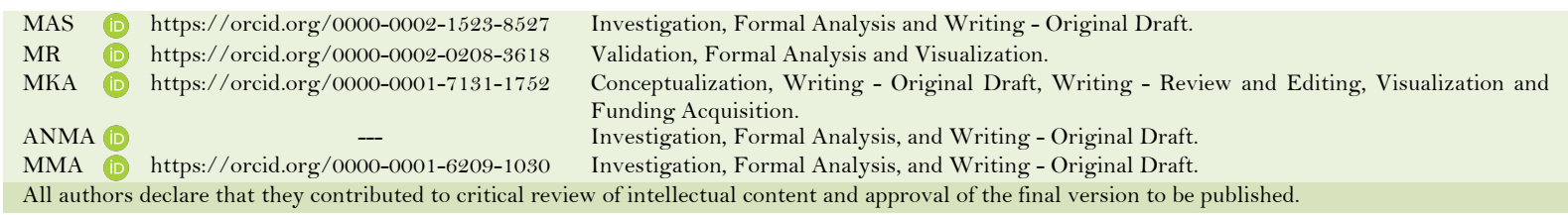

\section{Financial Support}

None.

\section{Conflict of Interest}

The authors declare no conflicts of interest.

\section{Data Availability}

The data used to support the findings of this study can be made available upon request to the corresponding author

\section{References}

[1] Baran GR. The metallurgy of Ni-Cr alloys for fixed prosthodontics. J Prosthet Dent 1983; 50(5):639-50. https://doi.org/10.1016/0022-3913(83)90201-9

[2] Leal MB, Paulino SM, Pagnano VO, Bezzon OL. Influence of investment type and sprue number on the casting accuracy of titanium crown margins. J Prosthet Dent 2006; 95(1):42-9. https://doi.org/10.1016/j.prosdent.2005.11.004

[3] Young HM, Coffey JP, Caswell CW. Sprue design and its effect on the castability of ceramometal alloys. J Prosthet Dent 1987; 57(2):160-4. https://doi.org/10.1016/0022-3913(87)90139-9

[4] Verrett RG, Duke ES. The effect of sprue attachment design on castability and porosity. J Prosthet Dent 1989; 61(4):418-24. https://doi.org/10.1016/0022-3913(89)90006-1

[5] Chan D, Guillory V, Blackman R, Chung KH. The effects of sprue design on the roughness and porosity of titanium castings. J Prosthet Dent 1997; 78(4):400-4. https://doi.org/10.1016/s0022-3913(97)70048-9

[6] Rieger MR, Tanquist RA, Vainer S. The effect of a new sprue design on the castability of a base-metal alloy. J Prosthet Dent 1986; 55(6):686-90. https://doi.org/10.1016/0022-3913(86)90443-9

[7] Peregrina A, Schorr BL. Comparison of the effects of three sprue designs on the internal porosity in crowns cast with a silver-free high-palladium alloy. J Prosthet Dent 1990; 64(2):162-6.

[8] Chai T, Stein R. Porosity and accuracy of multiple-unit titanium castings. J Prosthet Dent 1995; 73(6):534-41. https://doi.org/10.1016/So022-3913(05)80112-X

[9] DeWald E. The relationship of pattern position to the flow of gold and casting completeness. J Prosthet Dent 1979; 41(5):531-4. https://doi.org/10.1016/0022-3913(79)90087-8

[10] Calow CA, Bayer PD, Porter IT. The solid state bonding of nickel, chromium and nichrome sheets to $\alpha-\mathrm{Al} 2 \mathrm{O} 3$. J Mater Sci 1971; 6(2):150-5.

[11] Oruç S, Tulunoglu Y. Fit of titanium and a base metal alloy metal-ceramic crown. J Prosthet Dent 2000; 83(3):314-8. https://doi.org/10.1016/s0022-3913(00)70134-x

[12] Duncan JD. Casting accuracy of Nickel-chromium alloys: Marginal discrepancies. J Dent Restor 1980; 59(7):1164. https://doi.org/10.1177/00220345800590071301

[13] Chan DC, Blackman R, Kaiser DA, Chung K. The effect of sprue design on the marginal accuracy of titanium castings. J Oral Rehabil 1998; 25(6):424-9. https://doi.org/10.1046/j.1365-2842.1998.00268.x

[14] Nakhei M R, Ghanbarzadeh J, Goharian R. The effect of recast base metal alloys on crown's marginal accuracy. J Med Sci 2008; 8(6):599-602. https://doi.org/10.3923/jms.2008.599.602

[15] Blackman R, Baez R, Barghi N. Marginal accuracy and geometry of cast titanium copings. J Prosthet Dent 1992; 67(4):435-40. https://doi.org/10.1016/0022-3913(92)90068-1

[16] Brockhurst PJ, Mclaverty VG, Kasloff Z. A castability standard for alloys used in restorative dentistry. Oper Dent 1983; 8(4):130-9. 